\title{
Letter to the editor regarding "Failed reduction of posterior hip dislocation accompanied by femoral head fracture: causes and resolving strategy"
}

\author{
Tomonori Shigemura $^{1}$ (D) Masataka Miura $^{2} \cdot$ Yasuaki Murata $^{1}$ \\ Received: 31 October 2020 / Accepted: 9 November 2020 / Published online: 17 November 2020 \\ (C) SICOT aisbl 2020
}

We read with great interest the article titled "Failed reduction of posterior hip dislocation accompanied by femoral head fracture: causes and resolving strategy" by Chen et al. and would like to congratulate the authors for their study [1]. The authors conducted a radiological study to determine the potential causes of the failure of a closed reduction of a posterior hip dislocation combined with a femoral head fracture, and introduced a modified Allis manoeuvre to effectively reduce the combined injury in a closed fashion.

Although they have touched a highly pertinent topic in a scientific manner, the manoeuvre has several disadvantages. We would like to point this out, and introduce a new closed reduction technique using a traction table [2].

The modified Allis manoeuvre reported by the authors [1] have several disadvantages. First, the surgeon and assistants have to exert persistent power until reduction is achieved. In particular, the surgeon may have back pain because he has to pull the leg up in a stooping position. Second, this technique require at least three people: the surgeon held the thigh up to reduce the dislocation, and an assistant fixed the patient's pelvis with both hands, then another assistant constantly pulled the thigh towards the posterior side to retract the femoral head to the posterior side of the acetabulum. As a result, if there is only a single surgeon or physician at the hospital, it may be difficult for them to treat hip dislocations by using the manoeuvre. Third, the surgeon is at risk for fall from a stretcher or fluoroscopy table during performing the technique.

Tomonori Shigemura

tshigepon@yahoo.co.jp

1 Department of Orthopaedic Surgery, Teikyo University Chiba Medical Center, 3426-3 Anesaki, Ichihara, Chiba 299-0111, Japan

2 Department of Orthopaedic Surgery, Graduate School of Medicine, Chiba University, Chiba, Japan
We developed a new reduction technique using a traction table [2]. This reduction technique offers several advantages. First, the surgeon does not have to exert a superfluous force because of the use of the traction table. Second, this technique can be performed with the help of a small number of staff; indeed, theoretically, it can be performed by one person. Third, there is no risk of the surgeon falling from a fluoroscopy table.

We respectfully appreciate that Chen et al. provided us with this important study. However, our reduction method is recommended as it eliminates the disadvantages of the modified Allis manoeuvre.

\section{Compliance with ethical standards}

Conflict of interest The authors declare that they have no conflict of interest.

\section{References}

1. Chen W, Gao Z, Ma L (2020) Failed reduction of posterior hip dislocation accompanied by femoral head fracture: causes and resolving strategy. Int Orthop. https://doi.org/10.1007/s00264-02004856-8

2. Shigemura T, Miura M, Murata Y, Yamamoto Y, Maruyama J, Wada Y (2020) A new closed reduction technique using a traction table to treat a traumatic posterior dislocation of the hip joint. Orthop Traumatol Surg Res. 106(5):881-884. https://doi.org/10.1016/j.otsr. 2020.03.015

Publisher's note Springer Nature remains neutral with regard to jurisdictional claims in published maps and institutional affiliations. 